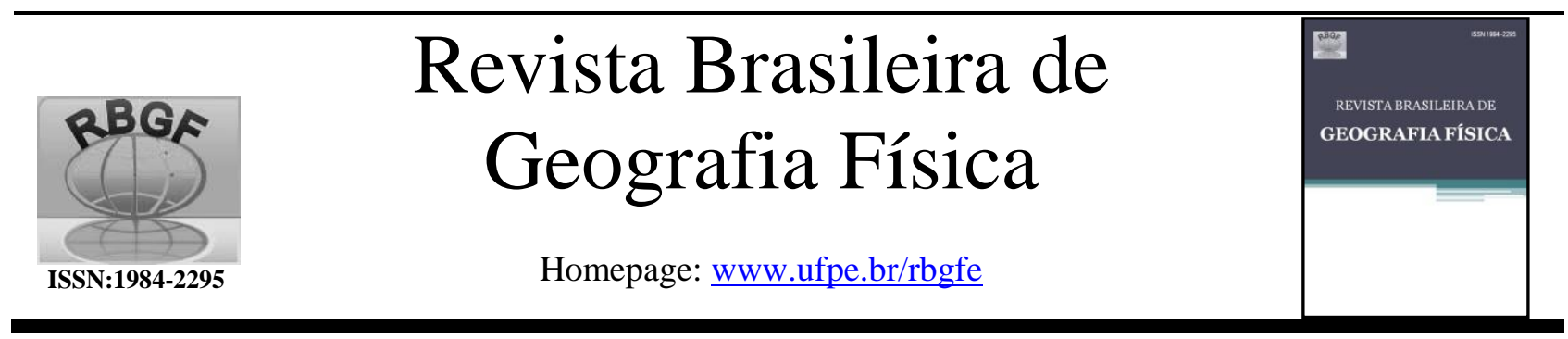

\title{
Carta de Materiais Inconsolidados: uma proposta visando à identificação da fragilidade do meio físico em área de expansão urbana
}

\author{
Alan Silveira ${ }^{1}$, Cenira Maria Lupinacci ${ }^{2}$ \\ 1. Prof. Dr. do Instituto de Geografia da Universidade Federal de Uberlândia (IG/UFU), Campus Monte Carmelo (MG), \\ alan.silveira@ufu.br. ${ }^{2}$. Prof ${ }^{a}$ Dr $^{a}$. do Departamento de Planejamento Territorial e Geoprocessamento da Universidade \\ Estadual Paulista (DEPLAN/IGCE/UNESP), Campus de Rio Claro. Coordenadora do Laboratório de Geomorfologia \\ (LAGEO), cenira@rc.unesp.br.
}

Artigo recebido em 27/01/2018 e aceito em 30/06/2018

\section{R E S U M O}

O objetivo desse artigo é propor uma adaptação da forma de análise da variável pedológica para o estabelecimento dos graus de fragilidade do meio físico (Ross, 1990, 1994 e 2001) para ambiente de expansão urbana, por meio de procedimentos da cartografia geotécnica. Para isso, foi organizada a carta de Materiais Inconsolidados da bacia do Córrego das Ondas (Piracicaba/SP) a partir dos procedimentos cartográficos apresentados por Pejon e Zuquette (1993) e Zuquette et al. (1994). Com o intuito de representar cartograficamente as características dos materiais que ocorrem do topo da rocha sã até a superfície, o documento cartográfico elaborado é produto de dados vinculados às características litológicas, à profundidade do material, à granulometria, à coloração e à permeabilidade, adquiridos em procedimentos de campo e de laboratório. Foram identificadas e mapeadas 7 classes de materiais inconsolidados para a bacia do Córrego das Ondas, as quais apresentam-se hierarquizadas em diferentes graus de fragilidade. Tais resultados adquiridos por meio dessa hierarquização poderão contribuir para a análise da fragilidade do meio físico em ambientes de expansão urbana. Palavras-chave: Materiais inconsolidados; fragilidade do meio físico; ambiente de expansão urbana.

\section{Map of Inconsolidated Materials: a proposal for the identification of fragility of the physical environment in urban expansion area}

\section{A B S T R A C T}

This article aims to suggest an adaptation of the pedological variable for the establishment of degrees of fragility (Ross, 1990, 1994 and 2001) for an urban expansion environment, through geotechnical cartography procedures. There for, we organized the map of inconsolidated materials from the basin of Córrego das Ondas (Piracicaba / SP), based on the cartographic procedures presented by Pejon and Zuquette (1993) and Zuquette et al. (1994). In order to map the characteristics of the materials from the top of the bedrock to the surface, the cartographic document produced is a product of data related to the lithological characteristics, material depth, particle size, color and permeability, acquired through field and laboratory procedures. Seven classes of unconsolidated materials were identified and mapped for the basin of Córrego das Ondas, which are hierarchical in different degrees of fragility. Such results acquired through this hierarchy may contribute to the analysis of fragility of the physical environment in urban expansion environments.

Keywords: Unconsolidated materials; Fragility of the physical environment; Environment of urban expansion.

\section{Introdução}

Partindo do pressuposto de que o conhecimento do meio físico é de suma importância para a melhor utilização e ocupação do solo, Maciel Filho (1997) destaca as áreas urbanas de crescimento acelerado e rápida ocupação, enfatizando que esse processo de expansão do espaço urbano nem sempre ocorre nas áreas mais adequadas (Maciel Filho, 1997). Christofoletti (2012), ao salientar a importância dos estudos do meio físico com ênfase a aplicabilidade da Geomorfologia, considera que a compreensão dos fluxos interativos do relevo com os demais componentes do geossistema (sistema ambiental físico) constitui-se em conhecimento relevante, o qual pode colaborar com o manejo e tomada de 
decisão para o estabelecimento de um uso da terra adequado. Nessa perspectiva, as características do geossistemas são expressas como resultantes da dinâmica interativa dos processos físicos $\mathrm{e}$ biológicos, recebendo inputs e incorporando produtos da ação humana (Christofoletti, 2012), como a expansão das cidades.

No âmbito da Geomorfologia brasileira, tem destaque os estudos que produzem cartas de Fragilidade, as quais reúnem informações de relevo, geologia, pedologia, climatologia e uso da terra/vegetação, voltadas para a análise das condições do meio físico a fim de subsidiar o planejamento de uso e ocupação das terras. Sob influência de Tricart (1977) e Tricart e Kiewietdjong (1992), com referência às análises morfodinâmicas ou ecodinâmicas, Ross (1990, 1994 e 2001) apresentou a proposta hierárquica das unidades de fragilidade natural e de fragilidade ambiental.

Tal metodologia propõe o estabelecimento de graus de fragilidade (níveis hierárquicos) para as variáveis do ambiente (relevo, geologia, pedologia, climatologia e uso da terra/vegetação) que posteriormente são sintetizadas em um documento cartográfico de Unidades de Fragilidade (Ross 1990, 1994 e 2001). Essa proposta visava originalmente à avaliação de ambientes rurais e, portanto, os dados pedológicos, inclusive aqueles vinculados a fertilidade, eram essenciais. Além disso, a proposta inicial era aplicada por vezes em grandes extensões de terras, oportunidades em que se faziam uso de mapeamentos já existentes (como os pedológicos), bem como se geravam mapeamentos de fragilidade em escalas de pouco detalhe.

Assim, tendo em vista que a proposta deste artigo apresenta como área de estudo um ambiente de expansão urbana, bem como trabalha em escala de detalhe, considera-se relevante a adaptação desse aspecto da metodologia. Essa adaptação da variável pedológica para o estabelecimento de graus de fragilidade (Ross, 1990, 1994 e 2001) para ambiente de expansão urbana, foi realizada considerando as perspectivas da cartografia geotécnica. Diniz (2012), ao tratar dos princípios da cartografia geotécnica, argumenta que a mesma trabalha na interface entre a Geologia de Engenharia e a Geomorfologia de Engenharia por meio da análise dos dados geológicos do meiofísico (relevo /material inconsolidado /rocha) com $\mathrm{o}$ intuito de prever o comportamento deste meio em face da ocupação antrópica.

Na temática da aplicação da cartografia geotécnica voltada ao planejamento urbano, com o interesse de evitar o número elevado de classificações (nomes de cartas e de unidades), Sobreira e Souza (2012) adotaram os termos cartas Geotécnicas de Suscetibilidades, cartas Geotécnicas de Aptidão à Urbanização e cartas Geotécnicas de Risco Geológico, reconhecendo que cada uma delas tem determinadas especificações, principalmente quanto aos objetivos de sua aplicação no contexto do planejamento urbano. Quanto às cartas de Suscetibilidade, os autores destacaram a contribuição da carta de Materiais Inconsolidados, como uma das informações básicas necessárias de entrada para a geração dos modelos (Sobreira e Souza, 2012).

Zaine (2000), ao estudar as metodologias e escolas de mapeamentos geotécnicos, faz menção à Escola de Engenharia de São Carlos EESC/USP, representada, sobretudo pela metodologia desenvolvida por Zuquette (1987 e 1993). Considera o autor que a proposição tem sido amplamente utilizada no âmbito nacional e caracteriza-se pela elaboração de mapas geotécnicos geralmente, na escala 1:100.000 e 1:50.000, que tratam de caracterizar o meio físico geológico e se destinam ao planejamento do uso do solo. Ainda, ao tratar da metodologia de Zuquette (1987 e 1993), Zaine (2000) complementa que o autor sugere que a escala geral/básica seja menor que 1:100.000, que a escala regional esteja entre $1: 100.000$ e 1:25.000, enquanto a de semidetalhe/detalhe deve estar entre 1:25.000 e 1:2.000.

Menciona-se essa escola de mapeamento geotécnico tendo em vista que seus trabalhos foram de grande interesse para esse artigo, sobretudo aqueles vinculados a Pejon e Zuquette (1993) e Zuquette et al. (1994) referentes, respectivamente, a metodologia de elaboração da carta de Potencial ao Escoamento Superficial e a metodologia da carta de Materiais Inconsolidados. Ambos os trabalhos foram reunidos no trabalho de Zuquette e Gandolfi (2004), que destacam a importância dos materiais inconsolidados para o uso da terra e as alterações que este uso propicia. Para os autores, a variedade dos tipos de materiais inconsolidados e sua distribuição espacial influenciam a eficiência dos usos e ocupações, bem como a intensidade dos impactos ambientais resultantes.

Feitas essas considerações iniciais, $\mathrm{o}$ artigo apresenta os procedimentos técnicos para a organização de uma carta de Materiais Inconsolidados com o intuito de aplicá-la como uma variável de entrada para a análise da fragilidade do meio físico. Dessa forma, tem por objetivo identificar o grau de fragilidade dos

Silveira, A., Lupinacci, C. M. 
materiais inconsolidados, tendo em vista que essa interpretação contribuirá como variável para a análise da fragilidade do meio físico. Mais especificamente, o artigo apresenta como contribuição procedimentos que visam a avaliação dos materiais inconsolidados para área de expansão urbana, considerando que essas informações podem subsidiar a identificação de níveis de restrição do relevo ao uso urbano. Trata-se, portanto, da aplicação da carta de Materiais Inconsolidados para a interpretação geomorfológica, sobretudo, quanto aos aspectos morfodinâmicos, voltados ao planejamento da ocupação urbana.

A carta de Materiais Inconsolidados elaborada foi organizada com adaptações às propostas de Pejon e Zuquette (1993) e de Zuquette et al. (1994). Nessa perspectiva, os materiais inconsolidados são compreendidos como materiais geológicos, residuais e retrabalhados, que ocorrem desde o topo da rocha sã até a superfície (Zuquette e Gandolfi, 2004).

Nestes termos, a área selecionada para aplicação da carta de Materiais Inconsolidados correspondeu à bacia hidrográfica do Córrego das Ondas, instalada no município de Piracicaba (SP), mais especificamente em área de expansão urbana, posicionada a noroeste do sítio urbano de Piracicaba e estabelecida entre as latitudes $22^{\circ} 38^{\prime} 30^{\prime \prime}$ e 22\%41',30', $\mathrm{S}$ e as longitudes $47^{\circ} 41^{\prime} 15^{\prime}$ ' e 4743'30', W (figura 1).

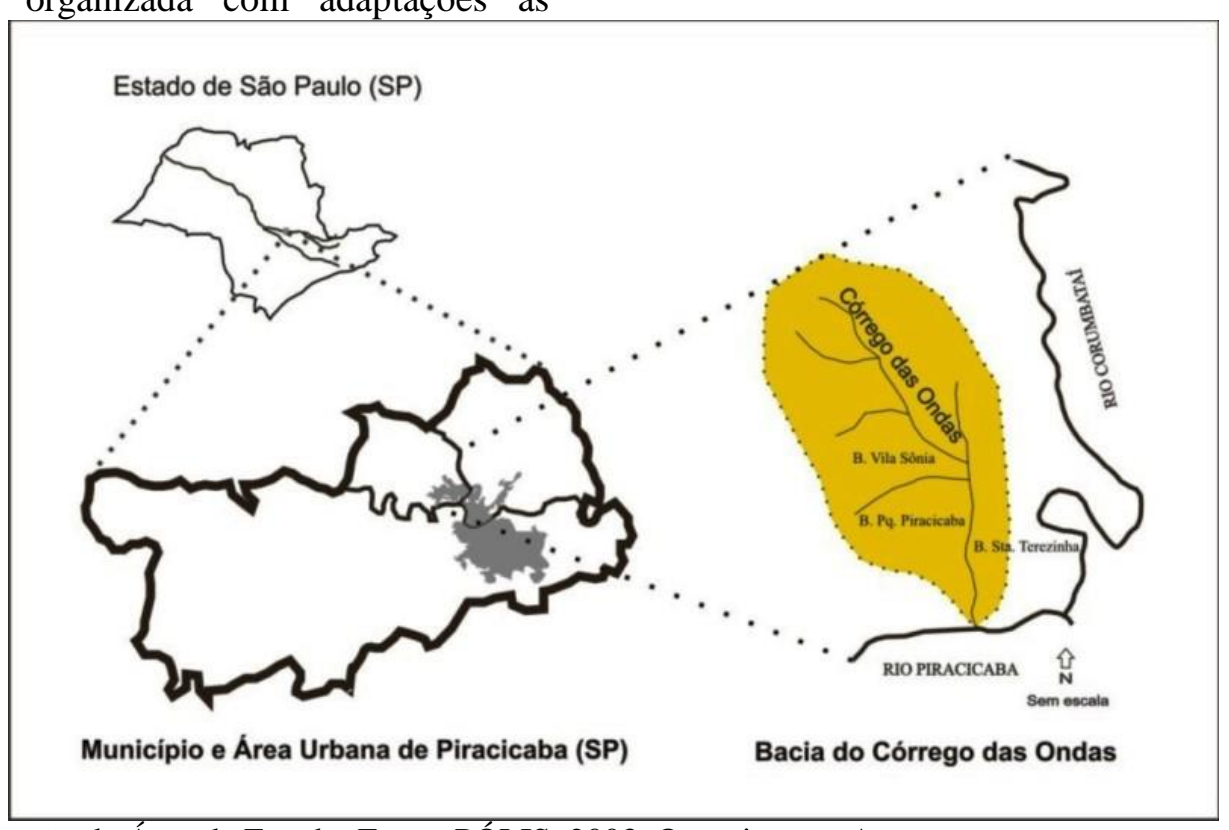

Figura 1: Localização da Área de Estudo. Fonte: PÓLIS, 2003. Organização: Autores.

De acordo com o Plano Diretor de 1991(PIRACICABA, 1991), a partir da década de 1960, a cidade passou a se expandir de maneira fragmentada, com a implementação de loteamentos públicos e privados distantes do eixo central. Eixos de expansão da malha urbana foram detectados, acusando os setores noroeste e sudeste como vetores de expansão (PIRACICABA, 1991 e PÓLIS, 2003). O Plano Diretor de Desenvolvimento do Município, aprovado em 2007 nos termos da Lei Complementar Municipal 186/2006 (PIRACICABA, 2006), identificou áreas com fragilidade ambiental no eixo de expansão urbana noroeste, apontando a necessidade do controle dessa expansão.

\section{Procedimentos Técnicos de Aplicação da Proposta Cartográfica}

Conforme mencionado, a carta de Materiais Inconsolidados da Bacia do Córrego das Ondas foi organizada a partir dos princípios da cartografia geotécnica apresentados por Pejon e Zuquette (1993) e Zuquette et al. (1994). O documento cartográfico de Materiais Inconsolidados de Zuquette et al. (1994) leva em consideração principalmente os aspectos texturais e genéticos, litológicos e de espessura para definição das unidades de materiais inconsolidados. Já o trabalho de Pejon e Zuquette (1993), por se tratar de uma carta de Potencial ao Escoamento Superficial, atribuiu como variáveis de análise a declividade, a litologia, a textura e gênese dos materiais inconsolidados, a espessura dos materiais inconsolidados, a permeabilidade, a frequência de drenagem e feições favoráveis ao armazenamento superficial. 
Assim, a carta de Materiais Inconsolidados da bacia do Córrego das Ondas foi elaborada por meio de adaptações aos trabalhos anteriores citados, considerando os seguintes aspectos:

- as contribuições/subsídios deste documento para a identificação do grau de fragilidade dos materiais inconsolidados, tendo em vista que essa interpretação contribuirá como variável para a análise da fragilidade do meio físico;

- as características da área estudada, as quais se relacionam com uma área de expansão urbana;

- a escala de mapeamento: o documento foi organizado na escala 1:10.000, ao passo que as metodologias de referência, no caso os trabalhos de Pejon e Zuquette (1993) e Zuquette et al. (1994), foram organizados, respectivamente, nas escalas 1:100.00 e 1:25:000.

Considerando esses interesses, que subsidiaram a aplicação da proposta metodológica cartográfica, foram definidas as seguintes variáveis para a composição das classes de materiais inconsolidados da bacia do Córrego das Ondas:

- litologia: levantamento dos diferentes tipos e das principais características do material rochoso com o intuito de contribuir para a leitura da origem dos materiais inconsolidados;

- espessura dos materiais inconsolidados: averiguação da profundidade dos materiais inconsolidados com o interesse em diagnosticar o grau de evolução intempérica e pedogenética do perfil;

- cor e textura dos materiais inconsolidados: verificação da variação das características morfológicas dos materiais inconsolidados ao longo do perfil/tradagem. Assim, por meio da observação em campo no processo de retirada do material com o trado, dando atenção às mudanças de coloração e textura, foi possível coletar diferentes amostras (superfície e subsuperfície), as quais foram encaminhadas ao laboratório para procedimentos de análise granulométrica e classe de textura. A identificação das diferentes características dos materiais inconsolidados ao longo do perfil auxilia o apontamento das áreas com materiais mais frágeis e mais resistentes aos processos erosivos, contribuindo para $\mathrm{o}$ planejamento da urbanização;

- permeabilidade de superfície: dado importante para a identificação dos materiais inconsolidados permeáveis e pouco permeáveis, qualidade as quais interferem diretamente na infiltração e no escoamento das águas pluviais. $\mathrm{O}$ apontamento das áreas de maior e menor permeabilidade também contribui para a avaliação dos materiais mais resistentes e mais suscetíveis aos processos erosivos.

Vale a justificativa quanto a aquisição dos dados das variáveis declividade, frequência de drenagem e feições favoráveis ao armazenamento superficial, conforme a proposta de Pejon e Zuquette (1993). Devido à escala, bem como á natureza geomorfológica do trabalho, tais dados foram adquiridos por meio de documentos cartográficos específicos. Para a determinação da fragilidade do meio físico, junto as informações adquiridas com a carta de Materiais Inconsolidados, também foram elaboradas por Silveira (2013) as cartas de Declividade (grau de inclinação do terreno), de Dissecação Horizontal (densidade de drenagem) e de Dissecação Vertical (grau de entalhamento dos vales), bem como ás cartas Geomorfológicas de detalhe, as quais foram essenciais, por exemplo, para a identificação e espacialização dos materiais inconsolidados derivados da dinâmica fluvial. Assim, esses dados advindos de Silveira (2013), foram analisados visando subsidiar a elaboração do documento cartográfico proposto nesse artigo.

Por meio de atividades vinculadas ao trabalho de campo, laboratório e gabinete, podem ser descritas etapas relevantes para a organização do mapeamento tratado:

- Uso da Base Cartográfica e fotografias aéreas em trabalhos de campo para orientação, localização e descrição dos pontos de observação e coleta de materiais. Tais pontos foram definidos a partir das áreas interfluviais, entre as principais drenagens afluentes do curso principal da bacia estudada. Procurou-se adquirir amostras representativas que contemplassem áreas de topo, média vertente e baixa vertente. A Base Cartográfica foi extraída das Cartas Topográficas do Plano Cartográfico do Estado de São Paulo, escala 1:10.000: Folhas Córrego das Ondas (SÃO PAULO, 1979a), Santa Terezinha do Piracicaba (SÃO PAULO, 1979b) e Piracicaba V (SÃO PAULO, 1979c); enquanto as fotografias áreas, disponibilizadas Instituto de Pesquisa e Planejamento de Piracicaba (IPPLAP), se encontram na escala aproximada de 1:25.000 (BASE, 2005);

- O levantamento dos dados geológicos foi realizado a partir dos seguintes materiais cartográficos: IGG (1966), escala 1:100.000; IPT (1981), escala 1:500.000; Sepe (1990), escala 1:50.000; Souza (2002), escala 1:100.000; e principalmente IPT (1980), na escala 1:25.000. Feita a etapa de aquisição de informações geológicas, foi realizada a etapa de pesquisa de 
campo para a aferição das diferentes litologias aflorantes;

- Uso do trado holandês para coleta das amostras deformadas e retirada de material inconsolidado até atingir a rocha sã para posterior medição da profundidade do perfil. Foram coletadas 60 amostras de superfície e subsuperfície em 36 pontos distribuídos pela bacia de estudo. As amostras de subsuperfície foram coletadas imediatamente após ter sido constatada uma mudança de coloração e textura no material retirado com o trado. Para verificação destas mudanças, além da observação em campo, se fez uso da Soil-Color Charts (MUNSELL, 2009). As amostras deformadas de superfície e subsuperfície foram encaminhadas ao Laboratório de Física de Solos do Departamento de Ciências do Solo da ESALQ USP, para procedimentos experimentais de análise granulométrica e classe de textura, a partir da análise SF1 (areia total, silte e argila com dispersante);

- Uso dos copos para coleta de 21 amostras indeformadas de superfície. Posteriormente a incisão completa do copo na superfície do material inconsolidado, retirou-se o mesmo com uso do martelo geológico, espátula e pá de jardim, para que a amostra fosse preservada ao máximo. Tais amostras foram encaminhadas para o Laboratório para Análise de Formações Superficiais (LAFS) do Departamento de Planejamento Territorial e Geoprocessamento, Deplan - IGCE - UNESP Campus de Rio Claro, para procedimentos experimentais de cálculo de coeficiente de permeabilidade $(\mathrm{cm} / \mathrm{s}$, fator $\mathrm{K})$, por meio do Permeâmetro de Carga Variável, fazendo uso do método B da NBR 14545 (ABNT, 2000).

Assim, as atividades mencionadas geraram os dados de: litologia, cor, relação textural, espessura dos materiais inconsolidados e a permeabilidade de superfície. Tais dados foram projetados na Base Cartográfica para definição e delimitação das classes de materiais inconsolidados. Para isso, adotaram-se os seguintes procedimentos:

- Setorização das diferentes litologias com auxílio dos dados geológicos, das observações do trabalho de campo e dos dados de coloração dos materiais inconsolidados;

- Com base nos valores adquiridos pela análise granulométrica e dos dados de espessura, procedeu-se o cálculo da relação textural por meio de procedimento da EMBRAPA (1999). Tais dados adquiridos, junto às observações determinadas em campo, possibilitaram a distinção e a setorização dos materiais inconsolidados em homogêneos e heterogêneos;

- Verificação dos valores das espessuras dos materiais inconsolidados para setorização dos materiais espessos ou pouco espessos;

- Aplicação e verificação dos coeficientes de permeabilidade para distinção de áreas com permeabilidade muito baixa $\left(10^{-5} \mathrm{~cm} / \mathrm{s}\right)$, baixa $\left(10^{-}\right.$ $\left.{ }^{4} \mathrm{~cm} / \mathrm{s}\right)$, média $\left(10^{-3} / \mathrm{s}\right)$, alta $\left(10^{-2} \mathrm{~cm} / \mathrm{s}\right)$;

- Reconhecimento e delimitação das áreas de materiais inconsolados resultantes da dinâmica fluvial a partir dos dados das cartas Geomorfológicas, elaboradas por Silveira (2013) e reambulados em campo.

\section{Resultados e discussão}

A partir dos procedimentos técnicos anteriormente descritos, foi possível a identificação e a espacialização das classes de materiais inconsolidados para a Bacia do Córrego das Ondas. A figura 2 ilustra o documento cartográfico resultante, enquanto o quadro 1 especifica em legenda as informações das classes mapeadas.

A bacia do Córrego das Ondas apresenta materiais inconsolidados derivados predominantemente da Formação Corumbataí e, em menor proporção, derivados de um restrito corpo intrusivo da Formação Serra Geral, que se localiza na porção norte da área estudada (figura 2b). No entanto, constatou-se o afloramento de diferentes fácies da Formação Corumbataí, tendo em vista que a porção oeste da bacia tem como característica a presença da fácie avermelhada (em maioria), enquanto a porção leste caracteriza-se por um material rochoso acinzentado (em menor extensão).

O limite/contato entre estas fácies aflorantes aproxima-se da drenagem principal do Córrego das Ondas, em sua baixa e média bacia. Nesta porção, observou-se um lineamento de drenagem, que indica uma possível falha (inferida), a qual provavelmente é o condicionante responsável pela estrutura dissimétrica da bacia do Córrego das Ondas, que apresenta um número significativo de drenagens afluentes concentradas na margem oeste do curso principal, dominadas pela fácie avermelhada da Formação Corumbataí (figura 2b). 
Revista Brasileira de Geografia Física v.11, n.04 (2018) 1371-1383.

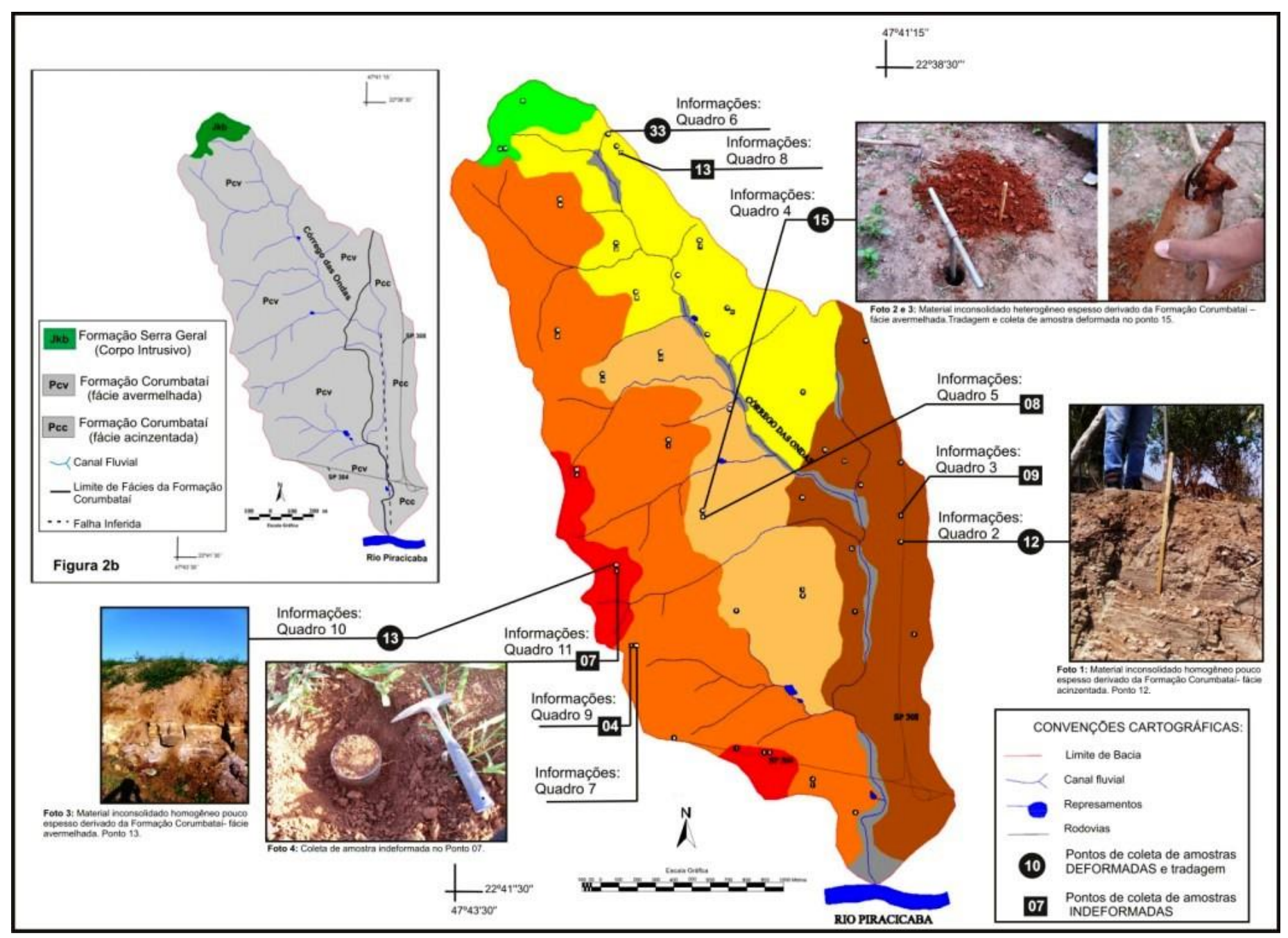

Figura 2: Carta de Materiais Inconsolidados da Bacia do Córrego das Ondas. Acompanhado de Mapa suplementar: figura 2b, que representa as formações geológicas da Bacia. 
Quadro 1: Classes de Materiais Inconsolidados da bacia do Córrego das Ondas - Piracicaba (SP).

\begin{tabular}{|c|c|}
\hline Cores na carta & CLASSES DE MATERIAIS INCONSOLIDADOS \\
\hline Verde & $\begin{array}{l}\text { Material homogêneo derivado da Formação Serra Geral, com espessura de } 10 \text { a } 70 \mathrm{~cm} \text {, } \\
\text { textura média argilosa a argilosa, coloração predominantemente vermelho-escuro- } \\
\text { acinzentado e permeabilidade baixa a média }\left(3,2 \times 10^{-4} \text { a } 1,6 \times 10^{-3} \mathrm{~cm} / \mathrm{s}\right)\end{array}$ \\
\hline Amarelo & $\begin{array}{l}\text { Material homogêneo espesso derivado da Formação Corumbatá́, com espessura de } 70 \\
\text { a } 300 \mathrm{~cm} \text {, textura média argilosa a muito argilosa, coloração predominantemente } \\
\text { vermelho-acinzentado e permeabilidade média }\left(1,4 \times 10^{-3} \text { a } 5,0 \times 10^{-3} \mathrm{~cm} / \mathrm{s}\right)\end{array}$ \\
\hline Laranja-claro & $\begin{array}{l}\text { Material heterogêneo espesso derivado da Formação Corumbataí, com espessura de } \\
90 \text { a } 170 \mathrm{~cm} \text {, textura média arenosa a muito argilosa, coloração predominantemente } \\
\text { vermelho-acinzentado e permeabilidade baixa a média }\left(5,2 \times 10^{-4} \text { a } 1,4 \times 10^{-3} \mathrm{~cm} / \mathrm{s}\right)\end{array}$ \\
\hline Laranja-escuro & $\begin{array}{l}\text { Material homogêneo espesso derivado da Formação Corumbatá́, com espessura de } 95 \\
\text { a } 236 \mathrm{~cm} \text {, textura média arenosa a argilosa, coloração predominantemente vermelho- } \\
\text { acinzentado e permeabilidade baixa }\left(1,4 \times 10^{-4} \text { a } 7,0 \times 10^{-4} \mathrm{~cm} / \mathrm{s}\right)\end{array}$ \\
\hline Vermelho & $\begin{array}{l}\text { Material homogêneo pouco espesso derivado da Formação Corumbataí, com } \\
\text { espessura de } 10 \text { a } 30 \mathrm{~cm} \text {, textura argilosa a muito argilosa, coloração } \\
\text { predominantemente vermelho-acinzentado e permeabilidade muito baixa a média }(3,7 \\
\left.\times 10^{-5} \text { a } 1,0 \times 10^{-3} \mathrm{~cm} / \mathrm{s}\right)\end{array}$ \\
\hline Marrom & $\begin{array}{l}\text { Material homogêneo pouco espesso derivado da Formação Corumbataí, com } \\
\text { espessura de } 05 \text { a } 30 \mathrm{~cm} \text {, textura média arenosa a argilosa, coloração } \\
\text { predominantemente cinzento-avermelhado e permeabilidade média a alta }\left(4,2 \times 10^{-3} \mathrm{a}\right. \\
\left.1,1 \times 10^{-2} \mathrm{~cm} / \mathrm{s}\right)\end{array}$ \\
\hline Cinza & Material derivado da dinâmica fluvial \\
\hline
\end{tabular}

Tais características litológicas aflorantes foram de suma importância para o início da delimitação das classes de materiais inconsolidados, considerando que este material é produto da ação intempérica do material rochoso. Da fácie acinzentada da Formação Corumbataí geram-se materiais inconsolidados homogêneos, pouco espessos (foto 1), de textura média arenosa a argilosa, com permeabilidade média a alta $\left(4,2 \times 10^{-3}\right.$ a $1,1 \times 10^{-2}$ $\mathrm{cm} / \mathrm{s}$ ). O quadro 2 exemplifica a reunião de dados adquiridos no ponto 12 (figura 2) a partir do trabalho em campo e da coleta de amostra deformada, com destaque aos valores de espessura $(30 \mathrm{~cm}$, foto 1$)$ e de coloração (cinzento-avermelhado). Já o quadro 3 ilustra o tratamento dos dados adquiridos no ponto 09 (figura 2), com a coleta de amostra indeformada para aquisição do coeficiente de permeabilidade de superfície em laboratório.

Quadro 2: Dados adquiridos no ponto 12.

\begin{tabular}{|c|c|c|c|c|}
\hline PONTO & $\begin{array}{c}\text { PERFIL } \\
\text { (espessura) }\end{array}$ & GRANULOMETRIA & $\begin{array}{c}\text { COR } \\
\text { (Classificação } \\
\text { Munsell) }\end{array}$ & $\begin{array}{c}\text { REGISTROS EM } \\
\text { CAMPO }\end{array}$ \\
\hline
\end{tabular}

\begin{tabular}{|c|c|c|c|c|c|c|c|c|}
\hline $\begin{array}{c}\text { Ponto/ } \\
\text { Número } \\
\text { amostra }\end{array}$ & $\begin{array}{c}\text { Setor/ } \\
\text { toponímia/ } \\
\text { uso da terra }\end{array}$ & & $\begin{array}{c}\text { Areia } \\
\text { total } \\
(\%)\end{array}$ & $\begin{array}{l}\text { Silte } \\
(\%)\end{array}$ & $\begin{array}{c}\text { Argila } \\
(\%)\end{array}$ & $\begin{array}{l}\text { Classe } \\
\text { de } \\
\text { textura }\end{array}$ & & \\
\hline 12 & $\begin{array}{c}\text { Alta } \\
\text { vertente/ } \\
\text { corte para } \\
\text { construção } \\
\text { de avenida/ } \\
\text { urbano }\end{array}$ & $30 \mathrm{~cm}$ & 49,9 & 22,3 & 27,8 & $\begin{array}{c}\text { Média } \\
\text { argilosa }\end{array}$ & $\begin{array}{c}\text { Cinzento- } \\
\text { avermelhado } \\
(7.5 \mathrm{R} 6 / 1)\end{array}$ & $\begin{array}{c}\text { Verificação e coleta no } \\
\text { perfil/corte para construção } \\
\text { de avenida/ } \\
\text { afloramento rochoso } \\
\text { acinzentado da formação } \\
\text { Corumbataí/ } \\
\text { presença afloramento de } \\
\text { água }\end{array}$ \\
\hline
\end{tabular}


Quadro 3: Dados adquiridos no ponto 09.

\begin{tabular}{|c|c|c|c|c|c|c|c|}
\hline \multicolumn{8}{|c|}{$\begin{array}{l}\text { PERMEÂMETRO DE CARGA VERIÁVEL - Método B da NBR } 14545 \\
\qquad \begin{array}{l}\text { K = aH } \mathbf{l n}(\mathbf{h} 1 / \mathbf{h} 2) \\
\mathbf{A} \mathbf{\Delta t}\end{array} \\
\text { da bureta de vidro }=6,6 \mathrm{~cm}^{2} ; \mathrm{H}=\text { altura inicial do corpo-de-prova = } 13 \mathrm{~cm} ; \mathrm{A}=\text { área inicial do corpo-de-prova } \\
\text { ela diferença entre os instantes } \mathrm{t} 2 \mathrm{e} \mathrm{t} 1=60 \mathrm{~s} ; \mathrm{H} 1=\text { carga hidráulica no instante } \mathrm{t} 1,(\mathrm{~cm}) ; \mathrm{H} 2=\text { carga } \\
2,(\mathrm{~cm}) ; \mathrm{K}=\text { coeficiente de permeabilidade, }(\mathrm{cm} / \mathrm{s}) \text {. }\end{array}$} \\
\hline $\begin{array}{l}\text { Ponto/ } \\
\text { Número } \\
\text { amostra }\end{array}$ & $\begin{array}{c}\text { Instantes } \\
(\mathrm{t} 1 \mathrm{e} \mathrm{t} 2)\end{array}$ & $\begin{array}{l}\text { Carga } \\
\text { Hidráulica } \\
(\mathrm{cm})\end{array}$ & $\begin{array}{c}\mathrm{Ln} \\
(\mathrm{h} 1 / \mathrm{h} 2)\end{array}$ & $\mathbf{K}=$ coefici & rmeabilidade & $\begin{array}{l}\text { Informações do material } \\
\text { inconsolidado de superfície }\end{array}$ & $\begin{array}{c}\text { Saída } \\
\text { permeâmetro } \\
(\mathrm{ml})\end{array}$ \\
\hline \multirow{8}{*}{ O9 } & $\mathrm{t} 1$ & 43,9 & 0,73 & 0,013 & \multirow{8}{*}{$1,1 \times 10^{-2}$} & \multirow{8}{*}{$\begin{array}{l}\text { Amostra com fragmento } \\
\text { rochosos acinzentados da } \\
\text { Formação Corumbataí na } \\
\quad \text { base. } \\
\text { Material exposto em área } \\
\quad \text { urbanizada }\end{array}$} & \multirow[t]{8}{*}{6100} \\
\hline & $\mathrm{t} 2$ & 21,0 & & & & & \\
\hline & $\mathrm{t} 1$ & 48,0 & \multirow[t]{2}{*}{0,61} & \multirow[t]{2}{*}{0,011} & & & \\
\hline & $\mathrm{t} 2$ & 26,0 & & & & & \\
\hline & $\mathrm{t} 1$ & 47,2 & \multirow[t]{2}{*}{0,56} & \multirow[t]{2}{*}{0,010} & & & \\
\hline & $\mathrm{t} 2$ & 26,7 & & & & & \\
\hline & $\mathrm{t} 1$ & 50,9 & \multirow[t]{2}{*}{0,52} & \multirow[t]{2}{*}{0,009} & & & \\
\hline & $\mathrm{t} 2$ & 30,0 & & & & & \\
\hline
\end{tabular}

Os dados ilustrados nos quadros mencionados corroboram com o enquadramento destes pontos na classe (figura 2, classe marrom) que indica material inconsolidado homogêneo derivado da fácie acinzentada da Formação Corumbataí.

Já a partir da fácie avermelhada da Formação Corumbataí geram-se materiais inconsolidados homogêneos e heterogêneos. Conforme mencionado, essa diferenciação foi avaliada em campo, a partir de dados de coloração e textura, bem como com base nos valores adquiridos pela análise granulométrica e dos dados de espessura, utilizados no cálculo da relação textural (EMBRAPA, 1999). Os materiais inconsolidados heterogêneos estão posicionados no centro da média bacia, apresentam textura de média arenosa a muito argilosa e valores de permeabilidade baixa a média $\left(5,2 \times 10^{-4}\right.$ a $1,4 \times 10^{-}$ $3 \mathrm{~cm} / \mathrm{s}$ ). As Fotos 2 e 3 (figura 2) registram o momento de procedimentos em campo no ponto 15, quando fazia-se uso do trado para avaliação da espessura e coleta de amostras deformadas. Os dados desse ponto, reunidos no quadro 4, apresentam valores diferenciados de espessura, granulometria e coloração em três segmentos de tradagem (15a, 15b e 15c). No quadro 5 são agrupados os dados adquiridos no ponto 8 , onde foi realizada a coleta de amostra indeformada. Tais dados observados nestas tabelas indicam materiais heterogêneos espessos, coloração dominante vermelho-escuro, textura média arenosa a argilosa e permeabilidade média, os quais foram enquadrados na classe "laranja-claro" (figura 2, material inconsolidado heterogêneo espesso derivado da Formação Corumbataí - fácie avermelhada).

Os materiais inconsolidados homogêneos derivados da fácie avermelhada da Formação Corumbataí foram subdivididos em espessos e pouco espessos. Os espessos foram localizados em duas porções da bacia do Córrego das Ondas com características distintas, relacionadas aos valores de textura e de permeabilidade. Na faixa leste (da média e alta bacia, figura 2), apresentam textura média argilosa a muito argilosa e permeabilidade média $\left(1,4 \times 10^{-3}\right.$ a $\left.5,0 \times 10^{-3} \mathrm{~cm} / \mathrm{s}\right)$. Aqueles encontrados na faixa oeste (da alta a baixa bacia, figura 2), apresentam textura média arenosa a argilosa e permeabilidade baixa $\left(1,4 \times 10^{-4}\right.$ a 7,0 x $\left.10^{-4} \mathrm{~cm} / \mathrm{s}\right)$. Para ilustrar essas diferenças, apresentam-se os quadros 6 (ponto 33, figura 2) e 7 (ponto 10, figura 2), bem como os quadros 8 (ponto 13, figura 2) e 9 (ponto 04, figura 2). Enquanto para os pontos presentes na faixa leste da alta e média bacia foram registrados matérias espessos de textura argilosa/média argilosa (quadro 6) e permeabilidade média $\left(1,4 \times 10^{-3}\right.$, quadro 8$)$, para a faixa oeste da alta a baixa bacia foram identificados materiais também espessos, porém caracterizados por textura argilosa e permeabilidade baixa $\left(6,8 \times 10^{-4}\right.$, quadro 9$)$. Diante das diferenças nas classes de textura e permeabilidade, foram diferenciados os materiais inconsolidados homogêneos derivados da fácie avermelhada da Formação Corumbataí entre as classes "amarelo" (figura 2, material inconsolidado homogêneo espesso derivado da Formação Corumbataí, faixa leste da alta e média bacia) e "laranja escuro" (figura 2, material inconsolidado homogêneo espesso derivado da 
Formação Corumbataí, faixa oeste da alta a baixa bacia).

Posicionados em áreas restritas no extremo oeste da média bacia, ocorrem os materiais inconsolidados pouco espessos derivados da fácie avermelhada da Formação Corumbataí, que se caracterizam pela textura argilosa a muito argilosa e permeabilidade muito baixa a média $\left(3,7 \times 10^{-5} \mathrm{a}\right.$ $1,0 \times 10^{-3} \mathrm{~cm} / \mathrm{s}$ ). A foto 3 (figura 2) ilustra o perfil pouco espesso dos materiais inconsolidados no ponto de coleta 13, para o qual foram registrados

Quadro 4: Dados adquiridos no ponto 15. coloração vermelho-escuro-acinzentado e textura argilosa. (quadro 10). Já a foto 4 (figura 2) corresponde ao ponto 07 no momento de coleta da amostra indeformada. O quadro 11 reúne os dados de tratamento dessa amostra, indicando permeabilidade baixa $\left(2,1 \times 10^{-4}\right)$. Dessa forma, os dados projetados nos quadros mencionados se enquadram na classe "vermelho", correspondente a material inconsolidado pouco espesso derivado da fácie avermelhada da Formação Corumbataí.

\begin{tabular}{|c|c|c|c|c|c|c|c|c|}
\hline \multicolumn{2}{|c|}{ PONTO } & \multirow{2}{*}{$\begin{array}{l}\text { PERFIL } \\
\text { (espessura) }\end{array}$} & \multicolumn{4}{|c|}{ GRANULOMETRIA } & \multirow{2}{*}{$\begin{array}{c}\text { COR } \\
\text { (Classificaçãa } \\
\text { o Munsell) }\end{array}$} & \multirow{2}{*}{$\begin{array}{c}\text { REGISTROS EM } \\
\text { CAMPO }\end{array}$} \\
\hline $\begin{array}{l}\text { Ponto/ } \\
\text { Número } \\
\text { amostra }\end{array}$ & $\begin{array}{c}\text { Setor/ } \\
\text { toponímia/ } \\
\text { uso da terra }\end{array}$ & & $\begin{array}{l}\text { Areia } \\
\text { total } \\
(\%)\end{array}$ & $\begin{array}{l}\text { Silt } \\
\mathrm{e} \\
(\%)\end{array}$ & $\begin{array}{c}\text { Argila } \\
(\%)\end{array}$ & $\begin{array}{c}\text { Classe } \\
\text { de } \\
\text { textura }\end{array}$ & & \\
\hline $15 \mathbf{a}$ & \multirow{3}{*}{$\begin{array}{c}\text { Média } \\
\text { vertente/ } \\
\text { canteiro } \\
\text { igreja vila } \\
\text { Sônia/ } \\
\text { urbano }\end{array}$} & $40 \mathrm{~cm}$ & 63,7 & 21,2 & 15,1 & $\begin{array}{l}\text { Média } \\
\text { arenosa }\end{array}$ & $\begin{array}{c}\text { Preto- } \\
\text { avermelhado } \\
7.5 \mathrm{R} 2.5 / 1\end{array}$ & \multirow{3}{*}{$\begin{array}{l}\text { Verificação e coleta com } \\
\text { uso do trado/Material bem } \\
\text { intemperizado, argiloso e } \\
\text { avermelhado/O material } \\
\text { coletado identificado } \\
\text { como "c" não se constituí } \\
\text { como horizonte } \\
\text { R/encontro de "camada } \\
\text { argilosa resistente } \\
\text { (piçarra)" avermelhada da } \\
\text { formação Corumbataí }\end{array}$} \\
\hline $15 b$ & & $20 \mathrm{~cm}$ & 46,9 & 35,4 & 17,7 & $\begin{array}{l}\text { Média } \\
\text { arenosa }\end{array}$ & $\begin{array}{l}\text { Vermelho muito } \\
\text { escuro- } \\
\text { acinzentado } \\
\text { 7.5R 2.5/4 }\end{array}$ & \\
\hline $15 c$ & & $110 \mathrm{~cm}$ & 16,9 & 24,3 & 58,9 & $\begin{array}{l}\text { Argilos } \\
\text { a }\end{array}$ & $\begin{array}{c}\text { Vermelho-escuro } \\
7.5 \mathrm{R} 3 / 6\end{array}$ & \\
\hline
\end{tabular}

Quadro 5: Dados adquiridos no ponto 08.

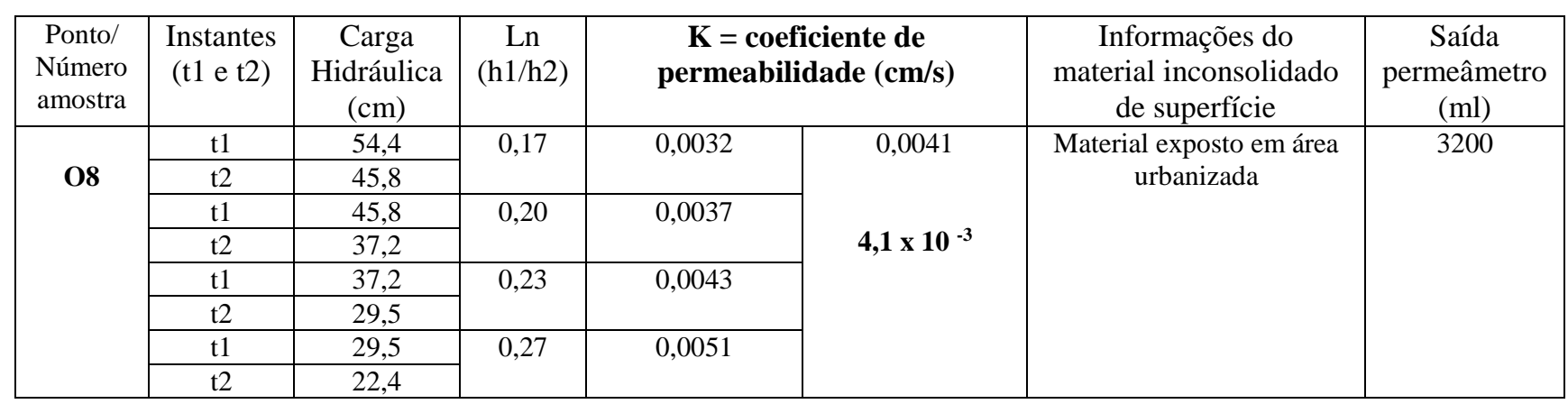

Quadro 6: Dados adquiridos no ponto 33.

\begin{tabular}{|c|c|c|c|c|c|c|c|c|}
\hline \multicolumn{2}{|c|}{ PONTO } & \multirow{2}{*}{$\begin{array}{l}\text { PERFIL } \\
\text { (espessura) }\end{array}$} & \multicolumn{4}{|c|}{ GRANULOMETRIA } & \multirow{2}{*}{$\begin{array}{c}\text { COR } \\
\text { (Classificação } \\
\text { Munsell) }\end{array}$} & \multirow{2}{*}{$\begin{array}{l}\text { REGISTROS EM } \\
\text { CAMPO }\end{array}$} \\
\hline $\begin{array}{l}\text { Pontos/ } \\
\text { Número } \\
\text { amostra }\end{array}$ & $\begin{array}{c}\text { Setor/ } \\
\text { toponímia/ } \\
\text { uso da terra }\end{array}$ & & $\begin{array}{l}\text { Areia } \\
\text { total } \\
(\%)\end{array}$ & $\begin{array}{l}\text { Silte } \\
(\%)\end{array}$ & $\begin{array}{l}\text { Argila } \\
(\%)\end{array}$ & $\begin{array}{l}\text { Classe } \\
\text { de } \\
\text { textura }\end{array}$ & & \\
\hline 33a & \multirow{2}{*}{$\begin{array}{c}\text { Alta } \\
\text { vertente/ } \\
\text { estrada de } \\
\text { terra Sta } \\
\text { Olímpia/ } \\
\text { canavial }\end{array}$} & $160 \mathrm{~cm}$ & 31,2 & 34,5 & 34,3 & $\begin{array}{c}\text { Média } \\
\text { argilosa }\end{array}$ & $\begin{array}{c}\text { Vermelho-escuro- } \\
\text { acinzentado } \\
5 \mathrm{R} 3 / 3\end{array}$ & \multirow[t]{2}{*}{$\begin{array}{l}\text { Verificação e coleta no } \\
\text { perfil/estrada de terra }\end{array}$} \\
\hline 33b & & $140 \mathrm{~cm}$ & 32,2 & 28,6 & 39,1 & Argilosa & $\begin{array}{l}\text { Vermelho-escuro- } \\
\text { acinzentado } \\
7.5 \mathrm{R} 3 / 3\end{array}$ & \\
\hline
\end{tabular}


Quadro 7: Dados adquiridos no ponto 33.

\begin{tabular}{|c|c|c|c|c|c|c|c|c|}
\hline \multicolumn{2}{|c|}{ PONTO } & \multirow{2}{*}{$\begin{array}{l}\text { PERFIL } \\
\text { (espessura) }\end{array}$} & \multicolumn{4}{|c|}{ GRANULOMETRIA } & \multirow{2}{*}{$\begin{array}{c}\text { COR } \\
\text { (Classificação } \\
\text { Munsell) }\end{array}$} & \multirow{2}{*}{$\begin{array}{l}\text { REGISTROS EM } \\
\text { CAMPO }\end{array}$} \\
\hline $\begin{array}{l}\text { Pontos/ } \\
\text { Número } \\
\text { amostra }\end{array}$ & $\begin{array}{c}\text { Setor/ } \\
\text { toponímia/ } \\
\text { uso da terra }\end{array}$ & & $\begin{array}{l}\text { Areia } \\
\text { total } \\
(\%)\end{array}$ & $\begin{array}{l}\text { Silte } \\
(\%)\end{array}$ & $\begin{array}{c}\text { Argila } \\
(\%)\end{array}$ & $\begin{array}{c}\text { Classe } \\
\text { de } \\
\text { textura }\end{array}$ & & \\
\hline $10 a$ & \multirow{2}{*}{$\begin{array}{c}\text { Alta } \\
\text { vertente/av } \\
\text { pq. } \\
\text { Piracicaba/u } \\
\text { rbano }\end{array}$} & $40 \mathrm{~cm}$ & 19,2 & 35,0 & 45,8 & Argilosa & $\begin{array}{c}\text { Vermelho-claro- } \\
\text { acinzentado } \\
7.5 \mathrm{R} 6 / 3\end{array}$ & \multirow[t]{2}{*}{$\begin{array}{l}\text { Verificação e coleta no } \\
\text { perfil/estrada de terra }\end{array}$} \\
\hline $10 \mathrm{~b}$ & & $180 \mathrm{~cm}$ & 24,1 & 33,3 & 42,7 & Argilosa & $\begin{array}{l}\text { Vermelho-claro } \\
7.5 \mathrm{R} 6 / 6\end{array}$ & \\
\hline
\end{tabular}

Quadro 8: Dados adquiridos no ponto 13.

\begin{tabular}{|c|c|c|c|c|c|c|c|}
\hline $\begin{array}{c}\mathrm{N}^{\mathrm{o}} \\
\text { amostra }\end{array}$ & $\begin{array}{c}\text { Instantes } \\
\text { (t1 e t2) }\end{array}$ & $\begin{array}{l}\text { Carga } \\
\text { Hidráulica } \\
(\mathrm{cm})\end{array}$ & $\begin{array}{c}\mathrm{Ln} \\
(\mathrm{h} 1 / \mathrm{h} 2)\end{array}$ & \multicolumn{2}{|c|}{$\begin{array}{c}K=\text { coeficiente de } \\
\text { permeabilidade }(\mathrm{cm} / \mathrm{s})\end{array}$} & $\begin{array}{l}\text { Informações do material } \\
\text { inconsolidado de } \\
\text { superfície }\end{array}$ & $\begin{array}{l}\text { Saída } \\
\text { permeâmetro } \\
(\mathrm{ml})\end{array}$ \\
\hline \multirow{8}{*}{13} & $\mathrm{t} 1$ & 30,2 & 0,068 & 0,0012 & \multirow{8}{*}{$\begin{array}{c}0,0014 \\
\mathbf{1 , 4} \times \mathbf{1 0}^{-3}\end{array}$} & \multirow{8}{*}{$\begin{array}{l}\text { Material com cana-de- } \\
\text { açúcar }\end{array}$} & \multirow[t]{8}{*}{3500} \\
\hline & $\mathrm{t} 2$ & 28,2 & & & & & \\
\hline & $\mathrm{t} 1$ & 28,2 & \multirow[t]{2}{*}{0,069} & \multirow[t]{2}{*}{0,0013} & & & \\
\hline & $\mathrm{t} 2$ & 26,3 & & & & & \\
\hline & $\mathrm{t} 1$ & 26,3 & \multirow[t]{2}{*}{0,079} & \multirow[t]{2}{*}{0,0014} & & & \\
\hline & $\mathrm{t} 2$ & 24,3 & & & & & \\
\hline & $\mathrm{t} 1$ & 24,3 & \multirow[t]{2}{*}{0,085} & \multirow[t]{2}{*}{0,0016} & & & \\
\hline & $\mathrm{t} 2$ & 22,3 & & & & & \\
\hline
\end{tabular}

Quadro 9: Dados adquiridos no ponto 04.

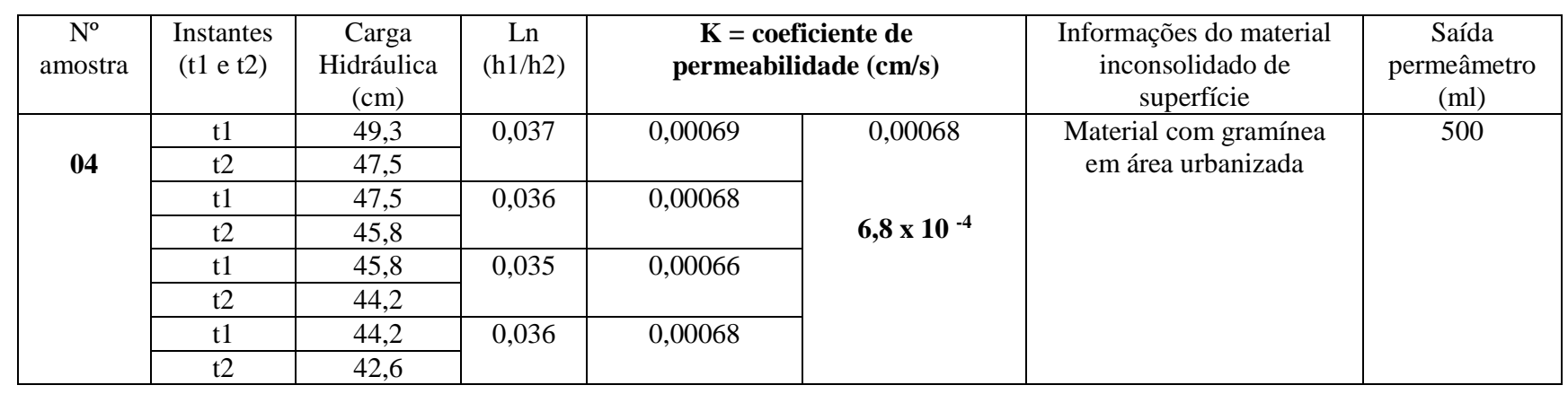

Quadro 10: Dados adquiridos no ponto 13.

\begin{tabular}{|c|c|c|c|c|c|c|c|c|}
\hline \multicolumn{2}{|c|}{ PONTO } & \multirow{2}{*}{$\begin{array}{c}\text { PERFIL } \\
\text { (espessura) }\end{array}$} & \multicolumn{4}{|c|}{ GRANULOMETRIA } & \multirow{2}{*}{$\begin{array}{c}\text { COR } \\
\text { (Classificação } \\
\text { Munsell) }\end{array}$} & \multirow{2}{*}{$\begin{array}{c}\text { REGISTROS EM } \\
\text { CAMPO }\end{array}$} \\
\hline $\begin{array}{l}\text { Pontos/ } \\
\text { Número } \\
\text { amostra }\end{array}$ & $\begin{array}{c}\text { Setor/ } \\
\text { toponímia/ } \\
\text { uso da terra }\end{array}$ & & $\begin{array}{c}\text { Areia } \\
\text { total } \\
(\%)\end{array}$ & $\begin{array}{l}\text { Silte } \\
(\%)\end{array}$ & $\begin{array}{c}\text { Argila } \\
(\%)\end{array}$ & $\begin{array}{c}\text { Classe } \\
\text { de } \\
\text { textura }\end{array}$ & & \\
\hline 13 & $\begin{array}{c}\text { Alta } \\
\text { vertente/av. } \\
\text { Corcovado/ } \\
\text { urbano }\end{array}$ & $10 \mathrm{~cm}$ & 22,7 & 33,8 & 43,5 & Argilosa & $\begin{array}{c}\text { Vermelho-escuro- } \\
\text { acinzentado } \\
\text { 10R } 3 / 2\end{array}$ & $\begin{array}{c}\text { Verificação e coleta com } \\
\text { uso do trado/material pouco } \\
\text { desenvolvido com presença } \\
\text { de pequenos "seixos } \\
\text { fragmentados" } \\
\text { avermelhados da formação } \\
\text { Corumbataí }\end{array}$ \\
\hline
\end{tabular}


Quadro 11: Dados adquiridos no ponto 07.

\begin{tabular}{|c|c|c|c|c|c|c|c|}
\hline $\begin{array}{c}\mathrm{N}^{\mathbf{0}} \\
\text { amostra }\end{array}$ & $\begin{array}{c}\text { Instantes } \\
(\mathrm{t} 1 \mathrm{e} \mathrm{t} 2)\end{array}$ & $\begin{array}{c}\text { Carga } \\
\text { Hidráulica } \\
(\mathrm{cm})\end{array}$ & $\begin{array}{c}\text { Ln } \\
(\mathrm{h} 1 / \mathrm{h} 2)\end{array}$ & \multicolumn{2}{|c|}{$\begin{array}{c}\mathbf{K}=\text { coeficiente de } \\
\text { permeabilidade }(\mathbf{c m} / \mathbf{s})\end{array}$} & $\begin{array}{c}\text { Informaçoses do material } \\
\text { inconsolidado de } \\
\text { superfície }\end{array}$ & $\begin{array}{c}\text { Saída } \\
\text { permeâmetro } \\
(\mathrm{ml})\end{array}$ \\
\hline \multirow{2}{*}{$\mathbf{0 7}$} & $\mathrm{t} 1$ & 50,2 & 0,010 & 0,00018 & 0,00021 & $\begin{array}{c}\text { Material exposto em área } \\
\text { urbanizada }\end{array}$ & 200 \\
\cline { 2 - 8 } & $\mathrm{t} 2$ & 49,7 & & & $\mathbf{2 , 1 \times 1 0} \mathbf{1 0}$ & & \\
\hline
\end{tabular}

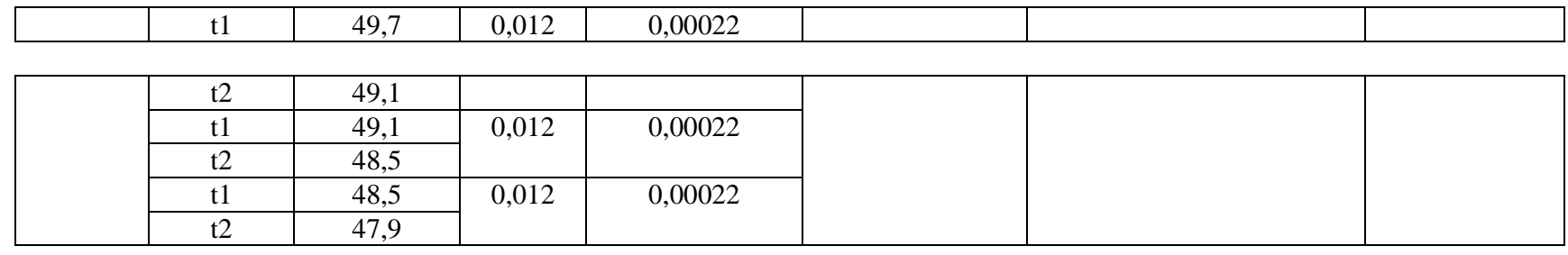

Por fim, no extremo norte da alta bacia, margeando o curso fluvial principal, encontram-se, respectivamente, os materiais inconsolidados derivados da Formação Serra Geral e materiais de áreas de acumulação fluvial. Os primeiros, de profundidade entre 10 a $70 \mathrm{~cm}$, registram textura média argilosa a argilosa e permeabilidade baixa a média $\left(3,2 \times 10^{-4}\right.$ a $\left.1,6 \times 10^{-3} \mathrm{~cm} / \mathrm{s}\right)$, ao passo que os segundos derivam da dinâmica em áreas de planícies e terraços fluviais (APTF). No mapa, correspondem as classes "verde" (figura 2, material inconsolidado homogêneo derivado da Formação Serra Geral) e "cinza" (figura 2, material inconsolidado derivado da dinâmica fluvial).

Dessa forma, considerando as classes de materiais inconsolidados identificadas e espacializadas (figura 2), por meio da análise integrada de suas características organizou-se uma hierarquia do grau de fragilidade desses materiais, como o intuito de utilizá-la como uma variável para a análise da fragilidade do meio físico. Os dados identificados vinculados ao tipo e característica do substrato rochoso, espessura do material, granulometria, coloração e permeabilidade, foram avaliados frente aos processos morfodinâmicos, sobretudo quanto à fragilidade potencial para o desenvolvimento de processos denudativos. O quadro 12 sintetiza os dados/elementos que interrelacionados foram classificados em graus de 1 a 7 , onde a própria tonalidade de cores indica as classes de menor para maior fragilidade.

\section{Considerações Finais}

Silveira, A., Lupinacci, C. M.
O trabalho partiu da premissa de que a identificação do grau de fragilidade dos materiais inconsolidados pode contribuir como variável para a análise da fragilidade do meio físico. Destaca-se a proposição de adaptação da variável pedológica para o estabelecimento de graus de fragilidade (Ross, 1990, 1994 e 2001), com o incremento de perspectivas da cartografia geotécnica. Os materiais inconsolidados, compreendidos como aqueles que ocorrem do topo da rocha sã até a superfície, foram tratados como a variável pedológica para a análise da fragilidade do meio físico, bem como caracterizados, espacializados e hierarquizados em graus de fragilidade.

Outro fator de destaque corresponde à questão da escala, tendo em vista que a área estudada correspondeu a um ambiente de expansão urbana. Tal fato exigiu um detalhamento da variável pedológica (materiais inconsolidados), com a necessidade de um número significativo de trabalhos de campo para verificação das características morfológicas dos materiais inconsolidados ao longo dos perfis/tradagens, coletas de amostras deformadas e indeformadas, bem como a leitura da variável em questão numa perspectiva geomorfológica, sobretudo frente aos processos morfodinâmicos, os quais subsidiaram a determinação dos graus de fragilidade dos materiais inconsolidados.

A partir dos dados vinculados ao tipo e característica do material rochoso, espessura do material, granulometria, coloração e permeabilidade, classificaram-se 7 classes de materiais inconsolidados para a bacia do Córrego 
das Ondas. Tais classes foram hierarquizadas em diferentes graus de fragilidade frente aos processos morfodinâmicos. Considera-se que os resultados adquiridos por meio dessa hierarquização poderão contribuir para a análise da fragilidade do meio físico em ambientes de expansão urbana.

Quadro 12: Classificação da fragilidade dos materiais inconsolidados da bacia do Córrego das Ondas - Piracicaba (SP).

\begin{tabular}{|c|c|c|}
\hline Elementos/dados determinantes & Classes de Materiais Inconsolidados & $\begin{array}{l}\text { Grau de } \\
\text { fragilidade dos } \\
\text { materiais } \\
\text { inconsolidados }\end{array}$ \\
\hline $\begin{array}{l}\text { - Material homogêneo derivado da Formação Serra } \\
\text { Geral; } \\
\text { - Textura média argilosa a argilosa, } \\
\text {-Permeabilidade baixa a média. }\end{array}$ & $\begin{array}{c}\text { Material inconsolidado homogêneo derivado } \\
\text { da Formação Serra Geral }\end{array}$ & 1 \\
\hline $\begin{array}{l}\text { - Material homogêneo espesso derivado da } \\
\text { Formação Corumbataí - fácie avermelhada; } \\
\text { - Textura média argilosa a muito argilosa; } \\
\text { - Permeabilidade média. }\end{array}$ & $\begin{array}{c}\text { Material inconsolidado homogêneo espesso } \\
\text { derivado da Formação Corumbataí, faixa } \\
\text { leste da alta e média bacia }\end{array}$ & 2 \\
\hline $\begin{array}{l}\text { - Material heterogêneo espesso derivado da } \\
\text { Formação Corumbataí - fácie avermelhada; } \\
\text { - Textura média arenosa a muito argilosa; } \\
\text { - Permeabilidade baixa a média. }\end{array}$ & $\begin{array}{c}\text { Material inconsolidado heterogêneo espesso } \\
\text { derivado da Formação Corumbataí }\end{array}$ & 3 \\
\hline $\begin{array}{l}\text { - Material homogêneo espesso derivado da } \\
\text { Formação Corumbataí - fácie avermelhada; } \\
\text { - Textura média arenosa a argilosa; } \\
\text { - Permeabilidade baixa. }\end{array}$ & $\begin{array}{c}\text { Material inconsolidado homogêneo espesso } \\
\text { derivado da Formação Corumbataí, faixa } \\
\text { oeste da alta a baixa bacia. }\end{array}$ & 4 \\
\hline $\begin{array}{l}\text { Material inconsolidado homogêneo pouco espesso } \\
\text { derivado da Formação Corumbataí - fácie } \\
\text { avermelhada; } \\
\text { - Textura argilosa a muito argilosa; } \\
\text { - Permeabilidade muito baixa a média. }\end{array}$ & $\begin{array}{l}\text { Material inconsolidado homogêneo pouco } \\
\text { espesso derivado da Formação Corumbataí }\end{array}$ & 5 \\
\hline $\begin{array}{l}\text { Material inconsolidado homogêneo pouco espesso } \\
\text { derivado da Formação Corumbataí - fácie } \\
\text { acinzentada; } \\
\text { - Textura média arenosa a argilosa; } \\
\text { - Permeabilidade média a alta. }\end{array}$ & $\begin{array}{l}\text { Material inconsolidado homogêneo pouco } \\
\text { espesso derivado da Formação Corumbataí }\end{array}$ & 6 \\
\hline $\begin{array}{l}\text { - Material resultante da dinâmica em áreas de } \\
\text { planícies e terraços fluviais (APTF) }\end{array}$ & $\begin{array}{c}\text { Material inconsolidado derivado da } \\
\text { dinâmica fluvial }\end{array}$ & 7 \\
\hline
\end{tabular}

\section{Agradecimentos}

Ao Conselho Nacional de Desenvolvimento Científico e Tecnológico $(\mathrm{CNPq})$ por propiciar a compra de materiais de campo e laboratório, que foram adquiridos por meio do Programa Chamada Universal (processo $\left.n^{\circ} 472550 / 2011-0\right)$.

\section{Referências}

ABNT. Associação Brasileira de Normas Técnicas, 2000. NBR 14545: Determinação do coeficiente de permeabilidade de solos argilosos a carga variável. Rio de Janeiro.

BASE. Aerofotogrametria e Projetos S/A, 2005. Fotografias Aéreas, escala: 1: 25.000. São Paulo.

Christofoletti, A., 2012. Aplicabilidade do Conhecimento Geomorfológico nos Projetos de Planejamento, in: Guerra, A.J.T., Cunha, S.B.C. 
(Org.), Geomorfologia uma atualização de Bases e Conceitos, $11^{\mathrm{a}}$ ed. Editora Bertrand Brasil, Rio de Janeiro, 415-437.

Diniz, N.C., 2012. Cartografia geotécnica por classificação de unidades de terreno e avaliação de suscetibilidade e aptidão. Revista Brasileira de Geologia de Engenharia e Ambiental [online] 2.2 Disponível: http://www.abge.com.br/wpcontent/uploads/2017/10/volume22017041921 310480345.pdf. Acesso: 10 ago. 2017.

EMBRAPA. Empresa Brasileira de Pesquisa Agropecuária, 1999. Sistema Brasileiro de Classificação dos Solos. Brasília.

IGG. Instituto Geográfico e Geológico do Estado de São Paulo, 1966. Folha Geológica de Piracicaba (SF 23-M 300), escala 1:100.000. São Paulo.

IPT. Instituto de Pesquisa Tecnológica do Estado de São Paulo, 1980. Mapa Geológico da Estrutura da Pitanga. São Paulo.

IPT. Instituto de Pesquisa Tecnológica do Estado de São Paulo, 1981. Mapa Geológico do Estado de São Paulo. São Paulo.

Maciel Filho, C.L., 1997. Introdução à Geologia de Engenharia, 2 ${ }^{\mathrm{a}}$ ed. Editora UFSM, Santa Maria.

MUNSELL. Munsell Color Sistem, 2009. SoilColor Charts. Michigan USA.

Pejon, O.J., Zuquette, L.V., 1993. Carta de Potencial de escoamento superficial da folha Piracicaba - SP. Geociências 2, 531-540.

PIRACICABA. Prefeitura Municipal de Piracicaba, 1991. Plano Diretor de Desenvolvimento de Piracicaba. Piracicaba.

PIRACICABA, 2006. Lei Complementar n. 186, de 10 de outubro.

PÓLIS. Instituto de Estudos, Formação e Assessoria em Políticas Sociais, 2003. Revisão do Plano Diretor de Desenvolvimento de Piracicaba: Relatório I - Leitura Técnica. São Paulo.

Ross, J.L.S., 1990. Geomorfologia, Ambiente e Planejamento. Ed. Contexto, São Paulo.

Ross, J.L.S., 1994. Análise Empírica da Fragilidade dos Ambientes Naturais Antropizados. Revista do Departamento de Geografia 8, 63-74.

Ross, J.L.S., 2001. Geomorfologia e Geografia Aplicadas a Gestão Territorial: Teoria e Metodologia para o Planejamento Ambiental. Tese (Livre Docência). São Paulo, FFLCHUSP.

SÃO PAULO. Secretaria de Economia e Planejamento, 1979a. Plano Cartográfico do Estado de São Paulo: Folha Córrego das Ondas
(070/088), Carta Topográfica, escala: 1: 10.000. São Paulo.

SÃO PAULO. Secretaria de Economia e Planejamento, 1979b. Plano Cartográfico do Estado de São Paulo: Folha Santa Terezinha do Piracicaba (071/088), Carta Topográfica, escala: 1: 10.000. São Paulo.

SÃO PAULO. Secretaria de Economia e Planejamento, 1979c. Plano Cartográfico do Estado de São Paulo: Folha Piracicaba V (071/089), Carta Topográfica, escala: 1: 10.000. São Paulo.

Sepe, P.M., 1990. Comportamento do Aqüífero Itararé no Município de Piracicaba e Áreas Vizinhas. Tese (Doutorado). Rio Claro, IGCEUNESP.

Silveira, A., 2013. Proposta metodológica para avaliação dos níveis de restrição do relevo ao uso urbano. Tese (Doutorado). Rio Claro, IGCE-UNESP.

Sobreira, F.G., Souza, L.A., 2012. Cartografia Geotécnica Aplicada ao Planejamento Urbano. Revista Brasileira de Geologia de Engenharia e Ambiental [online] 2. Disponível: http://www.abge.com.br/wpcontent/uploads/2017/10/volume22017041921 310480345.pdf. Acesso: 11 ago. 2017.

Souza, M.O.L., 2002. Evolução Tectônica dos Altos Estruturais de Pitanga, Artemis, Pau D'Alho e Jibóia - Centro do estado de São Paulo. Tese (Doutorado). Rio Claro, IGCEUNESP.

Tricart, J., 1977. Ecodinâmica. IBGE-SUPREN, Rio de Janeiro.

Tricart, J., Kiewietdjong, C., 1992. Ecogeography and Rural Managment. Longman Scientific e Techinical, Paris.

Zaine, J.E., 2000. Mapeamento geotécnico por meio do método do detalhamento progressivo. Tese (Doutorado). Rio Claro, IGCE-UNESP.

Zuquette, L.V., 1987. Análise crítica da cartografia geotécnica e proposta metodológica para as condições brasileiras. Tese (Doutorado). São Carlos, EESC-USP.

Zuquette, L.V., 1993. Importância do mapeamento geotécnico no uso e ocupação do meio físico: fundamentos e guia para elaboração. Tese (Livre Docência). São Carlos, EESC-USP.

Zuquette, L.V., Pejon, O.J., Sinelli, O., Gandolfi, N., 1994. Engineering geological zoning mapping of the Ribeirão Preto city (Brazil) at 1:25:000 scale. Congress of the International Association of Engineering Geology, 7, Lisboa.

Zuquette, L.V., Gandolfi, N., 2004. Cartografia Geotécnica. Editora de Textos, São Paulo. 